\title{
Arteriovenous Loops Enable Free Tissue Transfer With Otherwise Inadequate Local Donor and Recipient Vessels
}

\author{
MATHIAS TREMP ${ }^{1}$, CARLO M. ORANGES ${ }^{1}$, THOMAS WOLFF ${ }^{2}$, MARINA BARANDUN ${ }^{1}$, \\ ILARIO FULCO $^{1}$, HENRIK ECKARDT $^{3}$, DIRK J. SCHAEFER ${ }^{1}$ and DANIEL F. KALBERMATTEN ${ }^{1}$ \\ ${ }^{I}$ Department of Plastic, Reconstructive, Aesthetic and Hand Surgery, University Hospital Basel, Basel, Switzerland; \\ ${ }^{2}$ Department of Surgery, University Hospital Basel, Basel, Switzerland; \\ ${ }^{3}$ Department of Orthopaedic and Trauma Surgery, University Hospital Basel, Basel, Switzerland
}

\begin{abstract}
Background/Aim: Free flap reconstruction with damaged or diseased vessels is a challenging problem. We describe our case series using an arteriovenous loop or bypass surgery with free flaps for complex defect reconstructions at the lower extremity and the pelvic region. Patients and Methods: In this single-center retrospective cohort study 11 consecutive patients ( mean age $=73$ years, range $=53-88$ years) were operated on, between June 2016 and August 2018. Patients were reconstructed with free gracilis flaps $(n=8)$, free latissimus dorsi flap $(n=1)$ and chimeric scapular flap $(n=1)$, respectively. Results: The mean loop length was $30 \mathrm{~cm}$ (range $=12-40 \mathrm{~cm}$ ). The loop/bypass revision rate was $27 \%$ (3/11), and the overall flap loss rate was $20 \%$ (2/10). After a mean follow-up time of 17 months (range=12-24 months), the limb salvage rate was $75 \%$ (6/8). Conclusion: We successfully reconstructed complex defects with poor recipient vessels using arteriovenous loops or bypass surgery and free flaps.
\end{abstract}

Microsurgery can be very effective for the treatment of complex defects, with success rates of over $95 \%$ (1). For a successful implementation of surgery, healthy recipient vessels are mandatory. It is not unusual, however, that the vessels are damaged either by arteriosclerosis or trauma, and perforatorbased propeller flaps may not be feasible for reconstruction (1). In vascular trauma, vessels may be at a considerable distance from the defect, therefore long vein grafts are needed. However, this is associated with increased failure rates (2).

This article is freely accessible online.

Correspondence to: Mathias Tremp, MD, Plastic, Reconstructive, Aesthetic and Hand Surgery, University Basel, Spitalstrasse 21, 4031 Basel, Switzerland. Tel: +41 612652525, Fax: +41 612657301,e-mail: mathias.tremp@hin.ch

Key Words: Limb salvage, lower extremity, patient outcome assessment, perfusion, reconstructive surgical procedures.
In cases where an adequate recipient vessel or additional pedicle length is required, an arteriovenous loop or bypass surgery can be considered, with the ultimate goal to prevent lower extremity amputation $(3,4)$. The application of arteriovenous loops was reported to be a very powerful instrument with a constant high blood flow. Therefore, shunting the arterial and venous portion is established, allowing for a high-flow perfusion. Next, the free flap transfer can be performed either as a single-stage procedure, or at a second stage after perfusion has been established $(5,6)$.

Nevertheless, there is a paucity of data in the literature whether the one-stage or two-stage procedure provides greater success rates. While one-stage arteriovenous loops were reported to yield good results, two-stage arteriovenous loops were found to be associated with high graft occlusion, wound failure, and limb amputation rates (2). In all cases however, a large caliber grafts, such as the great saphenous vein with a relatively low resistance for bridging the defect, is required (2).

The aim of this study was to evaluate the outcome of patients with damaged vessels or arteriosclerosis who underwent reconstruction of complex soft tissue defects using arteriovenous loops or bypass surgery.

\section{Patients and Methods}

In this single-center retrospective cohort study 11 consecutive patients (mean age $=73$ years, range $=53-88$ years, eight males and three females) with a soft-tissue defect on the lower extremity or in the pelvic region with poor local donor or recipient vessels, were operated on, between June 2016 and August 2018. In one patient establishment of the arteriovenous loop and the defect reconstruction was performed in a one-stage procedure, whereas in the remaining patients defect reconstruction was performed two weeks after the loop $(n=9) /$ bypass $(n=1)$ operation (mean latency time between the loop/bypass and defect reconstruction was 16 days, range 7-20 days). In the two-stage procedures, Doppler probe was performed in all patients to assess loop/bypass patency before free flap transfer. Between establishment of the loops and free flap transfer, the patients received prophylactic subcutaneous low-molecular weight heparin (LMWH). Magnetic Resonance Angiography (MRA) was only 
Table I. Patient demographics and outcome.

\begin{tabular}{|c|c|c|c|c|c|c|c|c|}
\hline Gender/age & $\begin{array}{c}\text { Defect } \\
\text { location/Flap }\end{array}$ & Stage & Loop & $\begin{array}{l}\text { Loop } \\
\text { lengths }\end{array}$ & $\begin{array}{l}\text { Loop } \\
\text { re-exploration }\end{array}$ & Complications & $\begin{array}{l}\text { Limb } \\
\text { salvage }\end{array}$ & Follow-up \\
\hline $\mathrm{W} / 79$ & Malleolar/Gracilis & 2-stage & VSP & 35 & No & Flap loss & No & 24 \\
\hline $\mathrm{M} / 81$ & Heel/Gracilis & 1-stage & VSM & 25 & Yes & $\begin{array}{l}\text { Revision vascular pedicle, } \\
\text { wound healing problem flap }\end{array}$ & Yes & 16 \\
\hline $\mathrm{M} / 85$ & Malleolar/Gracilis & 2-stage & VSM & 12 & No & Mortality (hematoma, pneumonia) & NA & NA \\
\hline $\mathrm{M} / 83$ & Crural/Latissimus & 2-stage & VSM & 30 & No & $\begin{array}{l}\text { Partial flap loss, cardial } \\
\text { decompensation }\end{array}$ & Yes & 23 \\
\hline $\mathrm{M} / 69$ & Heel/Gracilis & 2-stage & VSM & 30 & No & Flap loss & No & 13 \\
\hline $\mathrm{M} / 62$ & Crural/Gracilis & 2-stage & VSM & 32 & No & None & Yes & 23 \\
\hline $\mathrm{M} / 69$ & Malleolar/Gracilis & 2-stage & VSM & 32 & No & Hematoma & Yes & 13 \\
\hline $\mathrm{M} / 77$ & Heel/Gracilis & 2-stage & VSM & 35 & No & Wound dehiscence & Yes & 14 \\
\hline $\mathrm{W} / 88$ & Crural/Gracilis & 2-stage & Bypass & - & Yes & $\begin{array}{c}\text { Mortality (pneumonia, } \\
\text { cardial decompensation) } \\
\text { Infection donor site } \\
\text { Revision vascular pedicle }\end{array}$ & NA & NA \\
\hline $\mathrm{W} / 55$ & $\begin{array}{c}\text { Crural/Chimeric Latissimus } \\
\text { Dorsi - Serratus }\end{array}$ & 2-stage & VSM & 32 & No & Partial flap loss (Serratus) & Yes & 12 \\
\hline $\mathrm{M} / 53$ & Pelvic region/None & NA & VSM & 40 & Yes & Loop occlusion & NA & 13 \\
\hline
\end{tabular}

F: Female; M: male; VSP: vena saphena parva; VSM: vena saphena magn; NA: not applicable.

performed where ultrasound was not conclusive. The VisionSense Iridium (Visionsense, Philadelphia, PA, USA) camera system was used to apply ICG-enhanced fluorescence $(0.1 \mathrm{mg} / \mathrm{kg}$; Verdye Diagnostic Green, Aschheim-Dornach, Germany) during surgery to assess regional hypoperfusion, arterial spasm or venous congestion in selected cases. No routine protocol was applied in this series, but exclusion criteria were: iodine allergy, autonomous adenoma of thyroid gland, hyperthyroidism or due to refusal by the patient (7).

We used free gracilis flaps in eight patients, and a free latissimus dorsi flap and a chimeric scapular flap in one patient each.

Immediately after surgery, the patient received a standard dose of 10,000 units of heparin infusion per $24 \mathrm{~h}$ for four days in total and then subcutaneous LMWH 5,000 units once daily until hospital discharge according to previous protocols $(8,9)$. Patients were ordered bed rest for five days, followed by mobilization under the supervision of a physical therapist as previously described (8). After hospital discharge, all patients were followed-up initially weekly to assess flap vitality as evaluated clinically and by hand-held ultrasound. Outcome evaluation included complications, loop/bypass re-exploration, flap loss, and limb salvage with a minimum follow-up of one year. Written informed consent was obtained from all patients, and the guidelines of the Declaration of Helsinki were followed accordingly.

\section{Results}

Patient demographics and outcomes are shown in Table I. Lower leg soft tissue defects after trauma were reconstructed in three patients, whereas the remaining patients had soft tissue loss due to severe atherosclerosis. Six patients were diagnosed with osteomyelitis, five patients with renal insufficiency, diabetes mellitus, or coronary heart disease, respectively. In 10 patients, the mean loop length was $30 \mathrm{~cm}$ (range $=12-40 \mathrm{~cm}$ ). Before flap transfer, ultrasound was performed in all patients, whereas MRA was performed in one patient where ultrasound was not conclusive (Figure 1). In nine patients, the great saphenous vein was used for the arteriovenous loop, whereas the small saphenous vein was used in one patient. The loop/bypass revision rate was $27 \%$, and overall flap loss rate was $20 \%$, one of whom was the patient using the small saphenous vein, which resulted in lower leg amputation. ICG-enhanced fluorescence was useful in assessing flap perfusion during surgery in three patients. According to previous reports $(10,11)$ intrinsic transit time (range $=20-30 \mathrm{~s}$ ) and transit flow time (<90 s) was regular in all cases, and complete free flap survival was observed in the follow-up period in those patients. In two patients, partial loss of the latissimus dorsi flap was observed, requiring debridement and reconstruction using a permanent skin substitute (Integra) with skin graft and serial debridement and healing by secondary intention. Free flap reconstruction in the pelvic region was not possible in one patient due to loop occlusion and several unsuccessful attempts for re-exploration. Wound closure was aimed by conservative wound management. Two patients died due to pneumonia and cardial decompensation. After a mean follow-up of 17 months (range=12-24 months), the limb salvage rate was $75 \%$ (Figures $2-4$ ).

\section{Discussion}

Temporary arteriovenous loops or bypass surgery provide adequate recipient vessels and flow to supply free flap tissue transfer in areas lacking recipient vessels and in which no other reconstructive options exist $(4,5)$. Czerny et al. assessed 

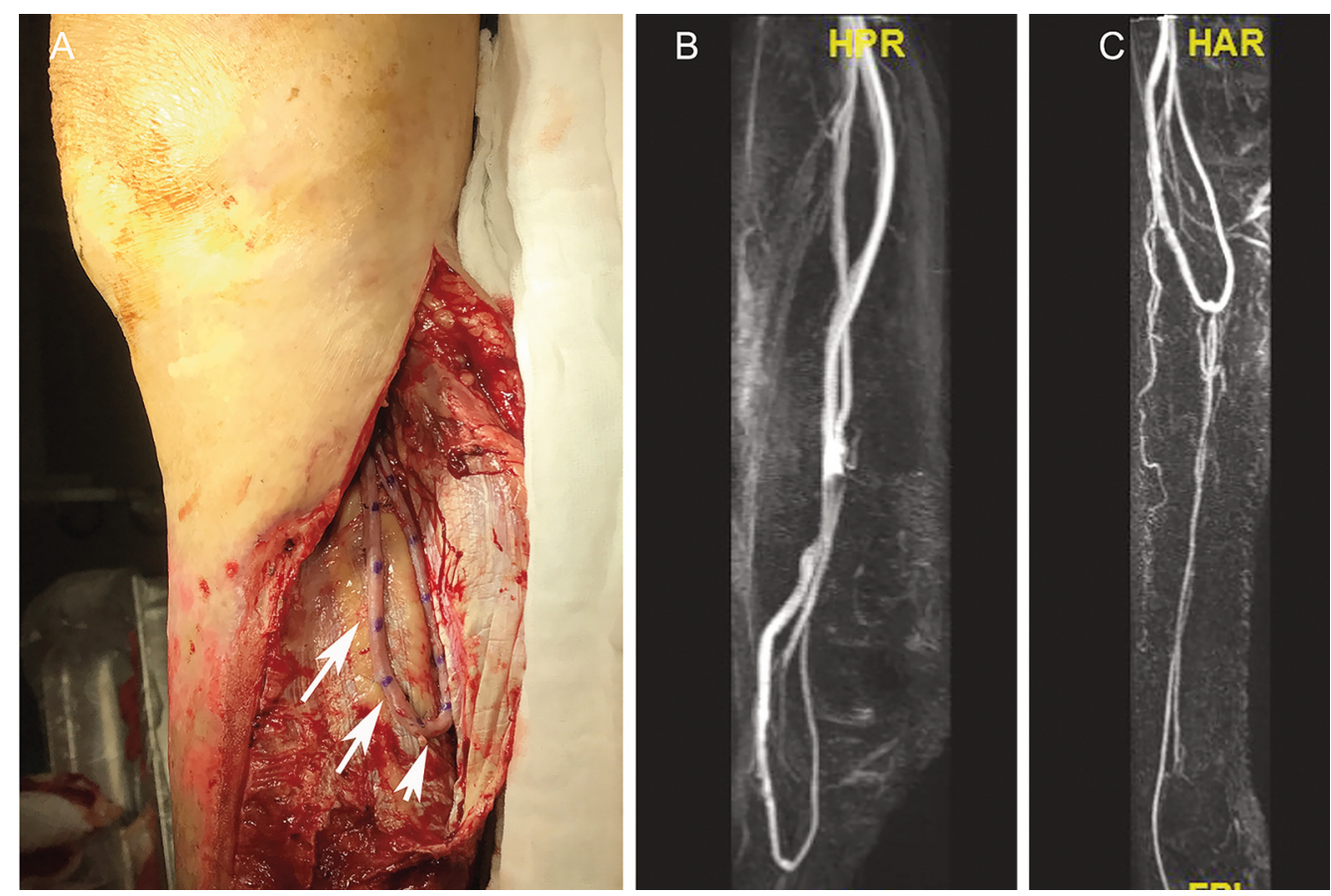

Figure 1. Arteriovenous loop. Representative arteriovenous loop (30 cm length) using the great saphenous vein harvested from the contralateral inguinal side anastomosed end-to-side to the popliteal vessels (A). Magnetic resonance angiography (MRA) showed loop patency before the second stage $(B, C)$.
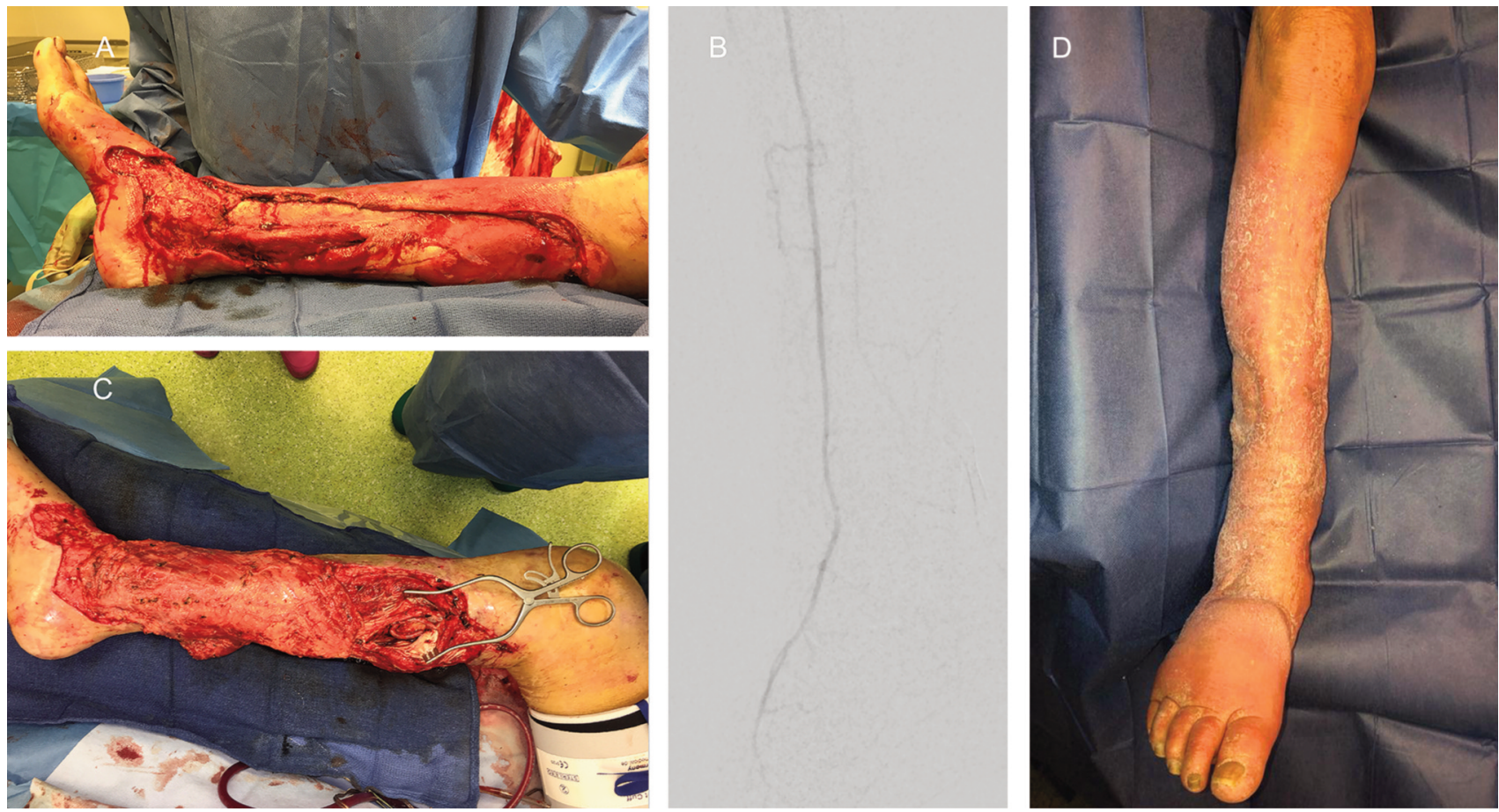

Figure 2. Case 1: A 72-year old male patient with diabetes mellitus was admitted with severe cellulitis of the right lower extremity (A). Angiography showed severe atherosclerosis with only patent anterior tibial artery $(B)$. After serial debridement, an arteriovenous loop $(30 \mathrm{~cm})$ was performed and anastomosed to the popliteal vessels. After 15 days, a free latissimus dorsi muscle was used for reconstruction (C). Distal flap necrosis occurred, requiring debridement and reconstruction using a permanent skin substitute (Integra) and skin graft three months later. After a follow-up of 23 months, stable soft tissue coverage was achieved $(D)$. 

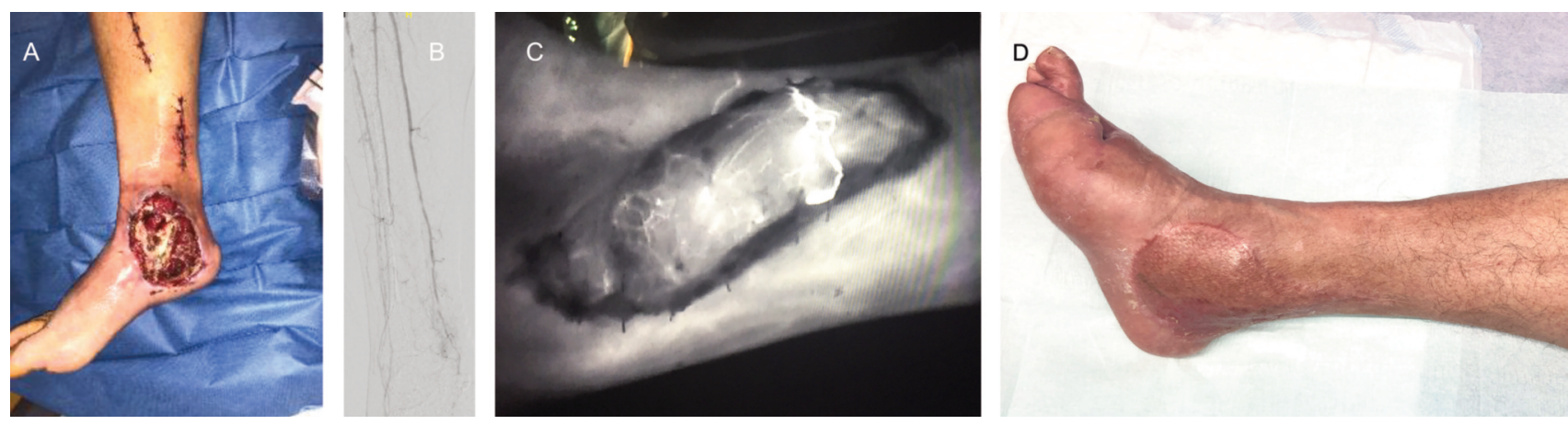

Figure 3. Case 2: A 67-year old male patient with diabetes mellitus was admitted with a soft tissue defect over the medial malleolus with osteomyelitis (A). Angiography showed severed atherosclerosis with severe stenosis of the anterior tibial artery (B). After serial debridement, an arteriovenous loop using the great saphenous venous was performed and anastomosed to the popliteal artery and concomitant tibial vein (loop length 32 cm). The free gracilis muscle was used for reconstruction seven days later. Intraoperative Indocyanine green (ICG) - enhanced fluorescence showed good perfusion of the flap $(C)$. Due to a burn injury five months later, transmetatarsal amputation I-III was required. After a follow-up of 13 months, stable soft tissue coverage was observed over the medial malleolus (D).

the long-term outcome of distal arterial reconstruction in combination with free muscle flap transfer using mainly the gracilis muscle for patients who would otherwise have undergone major amputation (12). After a mean follow-up of 51 months, the authors found that $77 \%$ of the reconstructions were patent, and that $70 \%$ of patients regained full functional capacity of their lower extremities (12).

Nevertheless, the use of arteriovenous loops in microsurgical lower extremity reconstruction is a controversial topic in the literature (13). In a recent study by Momeni et al., the utilization of vein grafts with creation of arteriovenous loops followed by single-stage division and free flap transfer for reconstruction of post-traumatic lower extremity defects achieved reconstructive outcomes similar to those obtained in patients in whom no vein grafts were necessary (13). It has been claimed that the decision of whether or not to use a staged flap transfer is dependent on the loop length: immediate transfer can be performed to vein segments of less than $20 \mathrm{~cm}$. Conversely, staged approaches can be performed in longer vein grafts (5). Moreover, the decision of whether or not to perform a simultaneous or subsequent flap transfer depends on the surgeon's experience, the surgeon's choice, the status of the wound and patient's pre-existing medical problems (5). Vogt et al. found no differences between simultaneous and staged flap transfer (5). Conversely, Lin et al. evaluated the outcome of patients that underwent arteriovenous loops followed by free tissue transfer in a one-stage $(n=28)$ and two-stage procedures $(n=6)$ (2). The authors reported a higher re-exploration rate $(33.3 \%$ vs. $28.6 \%)$, free flap failure rate $(33.3 \%$ vs. $10.7 \%)$, and lower limb salvage rate $(83.3 \%$ vs. $92.2 \%)$ in the two-stage procedure, compared to the one-stage procedure. This is in line with the results of Cavadas: the occlusion rate was $3 \%$ for one-stage loops and $16 \%$ for the two-stage loops (1). He also found more successful flaps in the one-stage procedure $(35 / 37)$ compared to the two-stage procedure (15/19), (1) which is probably due to kinking with turbulence at the most distal part of the graft, and postoperative swelling in the twostage procedure (2). In another study by Knackstedt et al., there was a statistically significant higher rate of major complications and failures in two-stage arteriovenous loops (14). However, in a recent study by Henn et al. evaluating 103 patients undergoing arteriovenous loop reconstruction, two-stage arteriovenous loop reconstructions did not lead to increased postoperative complications compared to one-stage arteriovenous loop reconstructions and may be favorable in complicated cases because of shorter operative times (15). Well-conducted randomized controlled studies are nearly impossible to perform in this population due to the complexity of the procedure and underlying medical conditions of the patients. Thus, the decision to pursue a single- versus two-stage reconstruction should be determined based on individual patient co-morbidities, and the type of free tissue transfer planned (14).

Delayed two-stage arteriovenous loops may have serious complications, including hemodynamic effects (cardiac failure) and steal phenomenon, leading to the possibility of aggravating distal ischemia (1). However, none of our patients suffered from steal phenomenon. Nevertheless, the staged transfer has been suggested to be more favorable also due to the shorter operative times, which is especially important in patients with multiple co-morbidities (2).

We used free gracilis and latissimus dorsi muscle flaps due to their large vessel caliber, which ensures a high flow with low resistance in combination with proximal large diameter vessels (large caliber vein grafts), proper size match and with the shortest possible vein graft length, according to the Poiseuille's and Ohms's law $(2,12)$. 

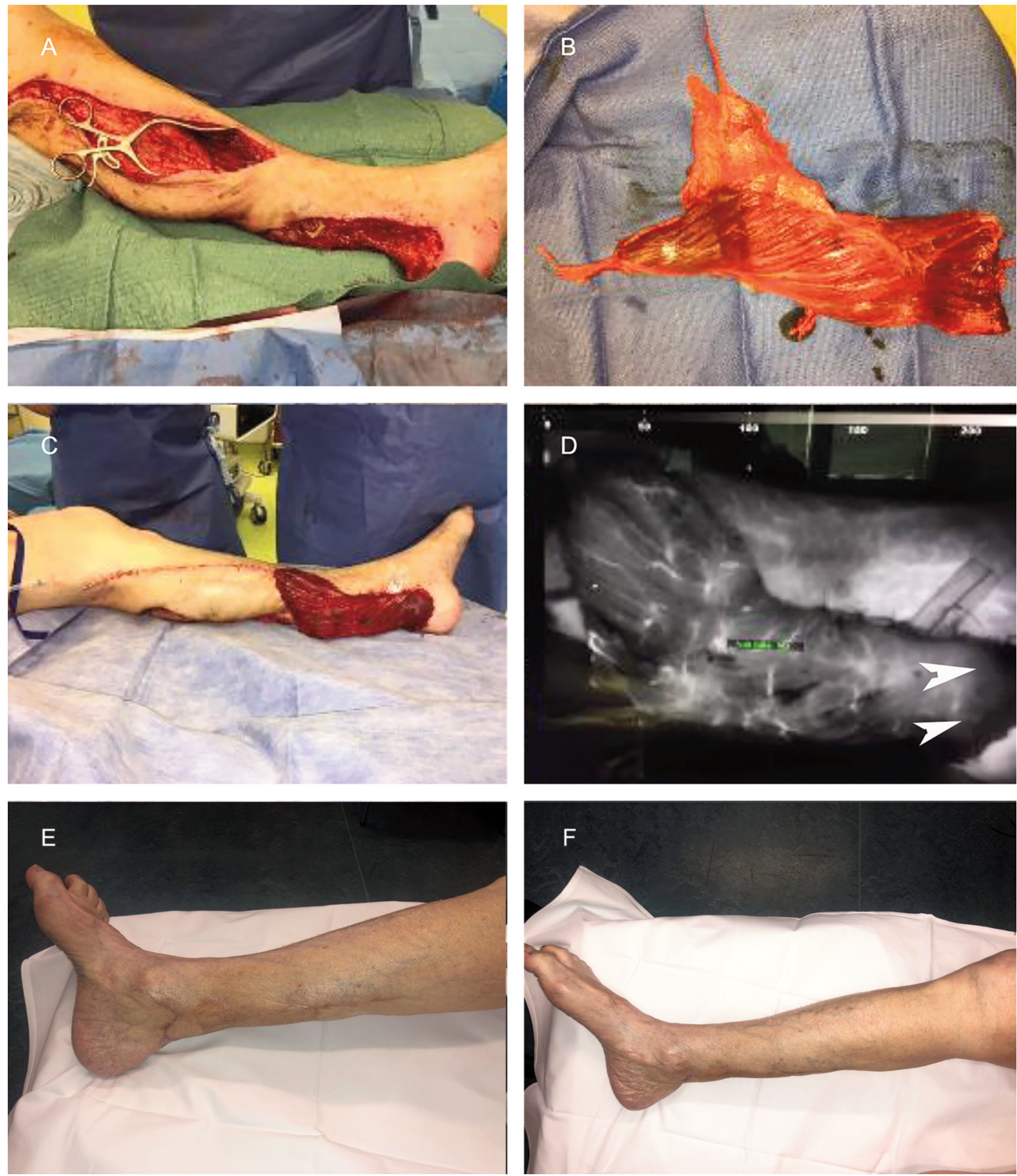

Figure 4. Case 3: A 76-year old male patient was admitted with an ulcer on the lower leg with arteriopathy, diabetes mellitus, deep vein thrombosis and chronic renal insufficiency. In the first stage, thrombectomy and arteriovenous loop with a great saphenous vein (loop length $35 \mathrm{~cm}$ ) anastomosed to the popliteal vessels was performed (A). After 16 days, the second stage was performed using the free gracilis muscle (B and C). Intraoperative ICG-enhanced fluorescence showed regional hypoperfusion (white arrow) of the muscle flap, requiring trimming of the distal part (D). After a follow-up of 14 months, stable soft tissue coverage was observed (E and F). 
Our study has certain limitations, such as a small sample size with a relatively short follow-up period, a lack of homogeneity and its retrospective nature. Thus, our results can be considered preliminary. More observational and largescale studies should be conducted with a long-term followup based on our preliminary results.

In conclusion, we successfully reconstructed lower extremity soft tissue defects with poor local donor and recipient vessels by means of arteriovenous loops or bypass surgery. The decision whether to pursue a single- versus twostage reconstruction should be determined based on individual patient co-morbidities, and the type of free tissue transfer planned.

\section{Conflicts of Interest}

The Authors declare that they have no conflicts of interest. None of the Authors has a financial interest in any of the products, devices, or drugs mentioned in this article.

\section{Authors' Contributions}

Study design: Mathias Tremp, Carlo M. Oranges, Daniel F. Kalbermatten; Data collection: Thomas Wolff, Marina Barandun, Ilario Fulco, Henrik Eckardt, Dirk J. Schaefer, Daniel F. Kalbermatten; Manuscript drafting: Mathias Tremp, Carlo M. Oranges, Daniel F. Kalbermatten; Critical revision: all Authors. Final approval: all Authors.

\section{Acknowledgements}

The Authors would like to thank Selina Ackermann for organizational workup and in revising our manuscript.

\section{References}

1 Cavadas PC: Arteriovenous vascular loops in free flap reconstruction of the extremities. Plast Reconstr Surg 121(2): 514-520, 2008. PMID: 18300970. DOI: 10.1097/01.prs. 0000297634.53915.e5

2 Lin CH, Mardini S, Lin YT, Yeh JT, Wei FC and Chen HC: Sixtyfive clinical cases of free tissue transfer using long arteriovenous fistulas or vein grafts. J Trauma 56(5): 1107-1117, 2004. PMID: 15179254. DOI: 10.1097/01.ta.0000114637.29779.ab

3 Cho HE, Roh SG, Lee NH and Yang KM: Breakthrough technique for free tissue transfer of poorly vascularized lower extremity: Arteriovenous loop revisited. Arch Plast Surg 42(5): 652-655, 2015. PMID: 26430646. DOI: 10.5999/aps.2015.42.5.652

4 Daigeler A, Kneser U, Fansa H, Riester T, Uder M, Horch RE and Deutschsprachige Gemeinschaft fur Mikrochirurgie der peripheren Nerven und G: [reconstruction of the vascular compromised lower extremity - report of the consensus workshop at the 35 . Meeting of the dam (deutschsprachige gemeinschaft fur mikrochirurgie der peripheren nerven und gefasse) 2013 in deidesheim]. Handchir Mikrochir Plast Chir 46(4): 248-255, 2014. PMID: 25162243. DOI: 10.1055/s-00341385851
5 Vogt PM, Steinau HU, Spies M, Kall S, Steiert A, Boorboor P, Vaske B and Jokuszies A: Outcome of simultaneous and staged microvascular free tissue transfer connected to arteriovenous loops in areas lacking recipient vessels. Plast Reconstr Surg 120(6): 1568-1575, 2007. PMID: 18040190. DOI: 10.1097/ 01.prs.0000282102.19951.6f

6 Freedman AM and Meland NB: Arteriovenous shunts in free vascularized tissue transfer for extremity reconstruction. Ann Plast Surg 23(2): 123-128, 1989. PMID: 2774439. DOI: 10.1097/00000637-198908000-00005

7 Ludolph I, Horch RE, Arkudas A and Schmitz M: Enhancing safety in reconstructive microsurgery using intraoperative indocyanine green angiography. Front Surg 6: 39, 2019. PMID: 31334246. DOI: 10.3389 /fsurg.2019.00039

8 Tremp M, Kappos EA, Oranges CM, di Summa PG, Schaefer DJ, Zhang YX, Wettstein R and Kalbermatten DF: Extending the limits of the anterior tibial artery as the recipient vessel for around the knee and proximal lower extremity defect reconstruction using the free anterolateral thigh and gracilis flap. Microsurgery 38(1): 60-65, 2018. PMID: 28233928. DOI: 10.1002/micr.30163

9 Tremp M, Wettstein R, Raffoul W, Schaefer DJ and Kalbermatten DF: Secret scar free gracilis flap. J Reconstr Microsurg 28(5): 341-344, 2012. PMID: 22588799. DOI: $10.1055 / \mathrm{s}-0032-1313765$

10 Holzbach T, Artunian N, Spanholtz TA, Volkmer E, Engelhardt TO and Giunta RE: [microscope-integrated intraoperative indocyanine green angiography in plastic surgery]. Handchir Mikrochir Plast Chir 44(2): 84-88, 2012. PMID: 22495959. DOI: $10.1055 / \mathrm{s}-0032-1309023$

11 Holm C, Dornseifer U, Sturtz G, Basso G, Schuster T and Ninkovic M: The intrinsic transit time of free microvascular flaps: Clinical and prognostic implications. Microsurgery 30(2): 91-96, 2010. PMID: 19790185. DOI: 10.1002/micr.20708

12 Czerny M, Trubel W, Zimpfer D, Grimm M, Koller R, Hofmann W, Holzenbein T, Polterauer P and Girsch W: Limb-salvage by femoro-distal bypass and free muscle flap transfer. Eur J Vasc Endovasc Surg 27(6): 635-639, 2004. PMID: 15121115. DOI: 10.1016/j.ejvs.2004.02.028

13 Momeni A, Lanni MA, Levin LS and Kovach SJ: Does the use of arteriovenous loops increase complications rates in posttraumatic microsurgical lower extremity reconstruction? -a matched-pair analysis. Microsurgery 38(6): 605-610, 2018. PMID: 28657669. DOI: 10.1002/micr.30197

14 Knackstedt R, Aliotta R, Gatherwright J, Djohan R, Gastman B, Schwarz G, Hendrickson M and Gurunluoglu R: Single-stage versus two-stage arteriovenous loop microsurgical reconstruction: A meta-analysis of the literature. Microsurgery 38(6): 706-717, 2018. PMID: 28738446. DOI: 10.1002/micr.30204

15 Henn D, Wahmann MST, Horsch M, Hetjens S, Kremer T, Gazyakan E, Hirche C, Schmidt VJ, Germann G and Kneser U: One-stage versus two-stage arteriovenous loop reconstructions: An experience on 103 cases from a single center. Plast Reconstr Surg 143(3): 912-924, 2019. PMID: 30624338. DOI: 10.1097/ PRS.0000000000005386 